\title{
Regulation of ovarian function: the role of anti-Müllerian hormone
}

\author{
Alexandra L. L. Durlinger, Jenny A. Visser \\ and Axel P. N. Themmen \\ Department of Internal Medicine, Erasmus MC, PO Box 1738, 3000 DR Rotterdam, \\ The Netherlands
}

\begin{abstract}
Anti-Müllerian hormone (AMH), also known as Müllerian inhibiting substance, is a member of the transforming growth factor $\beta$ superfamily of growth and differentiation factors. In contrast to other members of the family, which exert a broad range of functions in multiple tissues, the principal function of $\mathrm{AMH}$ is to induce regression of the Müllerian ducts during male sex differentiation. However, the patterns of expression of $\mathrm{AMH}$ and its type II receptor in the postnatal ovary indicate that $\mathrm{AMH}$ may play an important role in ovarian folliculogenesis. This review describes several in vivo and in vitro studies showing that $\mathrm{AMH}$ participates in two critical selection points of follicle development: it inhibits the recruitment of primordial follicles into the pool of growing follicles and also decreases the responsiveness of growing follicles to $\mathrm{FSH}$.
\end{abstract}

In 1947 it was shown that during development of the male fetus a testicular factor distinct from testosterone caused regression of the Müllerian ducts, which form the anlagen of the female genital tract (Jost, 1947; Munsterberg and LovellBadge, 1991). This factor was called anti-Müllerian hormone $(\mathrm{AMH})$ and was subsequently identified as a dimeric glycoprotein related to transforming growth factor $\beta$ (TGF $\beta$ ) (Cate et al., 1986). Together with inhibins, activins, bone morphogenetic proteins (BMPs), and growth and differentiation factors (GDFs), AMH is part of the TGF $\beta$ superfamily of peptide growth and differentiation factors (Massagué, 1990). Members of this family have a broad range of functions in mesenchymal-epithelial interactions, cell growth, extracellular matrix production and tissue remodelling (Massagué and Chen, 2000). In men, strong AMH expression is found in Sertoli cells from the moment of testicular differentiation during fetal development up to puberty, whereas in women $\mathrm{AMH}$ is produced by ovarian granulosa cells from about week 36 of gestation to menopause (Lee et al., 1996; Rajpert-De Meyts et al., 1999).

\section{AMH receptors}

Members of the TGF $\beta$ family signal through two related transmembrane serine-threonine kinase receptors, referred to as type I and type II receptors. Upon binding of the ligand to its type II receptor, the type I receptor is recruited to form a heterotetrameric receptor complex. Activation of the type I receptor through transphosphorylation by the type II receptor leads to subsequent downstream signalling via

Email: Durlinger@endov.fgg.eur.nl
Smad proteins (for a review, see Massagué and Chen, 2000).

The type II receptor for AMH (AMHRII) was cloned several years ago (rat: Baarends et al., 1994; rabbit: di Clemente et al., 1994a). Expression of AMHRII mRNA was found in the mesenchymal cells surrounding the Müllerian ducts (Baarends et al., 1994) and, in addition, in fetal and adult gonads of both sexes. Generation of AMHRII-deficient mice proved that this type II receptor is essential for $\mathrm{AMH}$ signalling, as demonstrated by the lack of Müllerian duct regression in AMHRII-deficient male mice (Mishina et al., 1996). In addition, the relevance of this receptor to $\mathrm{AMH}$ action was further demonstrated by the identification of mutations in the AMHRII gene of patients with persistent Müllerian duct syndrome (PMDS) (Imbeaud et al., 1996; Josso et al., 1997).

More insight into the identity of the AMH type I receptor has been gained recently. Members of the TGF $\beta$ family can use several different type I receptors to exert their effects. Two distinct sets of type I receptors can be made. Activin receptor-like kinase 1 (ALK1), ALK4 and ALK5 form the TGF $\beta$-activin group of type I receptors, whereas ALK2, ALK3 and ALK6 form the BMP group (Nakao et al., 1997; Massagué and Chen, 2000). It has been shown that AMH signals via the type I receptors of the BMP group. Experiments in vitro and organ culture experiments ex vivo, using an anti-sense oligo approach, revealed that ALK2 is involved in $\mathrm{AMH}$-induced Müllerian duct regression (Visser et al., 2001). ALK2-deficient mice are embryonically lethal and therefore do not provide additional information on ALK2 functioning as an AMH type I receptor. Generation of ALK3 conditional knockout mice showed that ALK3 might be involved in $\mathrm{AMH}$ signalling during induced Müllerian 
duct regression (for a review, see Teixeira, 2001); however, the role of ALK6 in AMH signalling is still questionable. Studies in vitro showed an AMH-dependent interaction between AMHRII and ALK6 (Gouedard et al., 2000). However, antisense ALK6 oligos or mutated ALK6 functioning as a dominant negative type I receptor did not disrupt AMH signalling (Clarke et al., 2001; Visser et al., 2001) and male ALK6-deficient mice do not retain their Müllerian ducts. These observations indicate that ALK6 is, at least during Müllerian duct regression, not crucial as an AMH type I receptor (Clarke et al., 2001). Together, these results indicate that $\mathrm{AMH}$, like BMPs, might signal through different type I receptors in a tissue- and cell-specific manner. Further studies are necessary to elucidate which signal transduction pathway is used by $\mathrm{AMH}$ in the ovary.

\section{Expression of AMH and its receptors in the ovary}

In contrast to its expression in male mice and rats, $\mathrm{AMH}$ is not expressed in female rodents before birth (Munsterberg and Lovell-Badge, 1991; Hirobe et al., 1992; Taketo et al., 1993; J. A. Visser and A. P. N. Themmen, unpublished), and this lack of expression guarantees a normal differentiation of the female internal reproductive tract structures. However, a few days after birth, this sexually dimorphic pattern of expression of $\mathrm{AMH}$ disappears and $\mathrm{AMH}$ expression is easily detected in granulosa cells of growing follicles (Ueno et al., 1989; Hirobe et al., 1992; Durlinger et al., 2002). In mice and rats, $\mathrm{AMH}$ displays a specific window of expression. It is first detected in the granulosa cells of early primary follicles (Munsterberg and Lovell-Badge, 1991; Taketo et al., 1993; Durlinger et al., 2002). Expression is highest in granulosa cells of preantral and small antral follicles (Fig. 1a). Within these follicles, $\mathrm{AMH}$ expression is not always evenly distributed, as in some follicles expression is highest in the granulosa cells immediately surrounding the antrum and around the oocyte (Fig. 1b) (Ueno et al., 1989; Hirobe et al., 1992, 1994; Baarends et al., 1995; Durlinger et al., 2002). This gradient of $\mathrm{AMH}$ expression within a follicle may reflect functional differences between the granulosa cells surrounding the oocyte and the more peripheral granulosa cells, such as differences in proliferation capacity and steroidogenic activity (Baarends et al., 1995). These functional differences may arise under the influence of factors produced by the oocyte, as has been shown for oocyte factor GDF9 (Elvin et al., 1999a). Some studies report that, in rats, $\mathrm{AMH}$ expression can be found until the preovulatory stage (Ueno et al., 1989; Hirobe et al., 1994), whereas other studies report that $\mathrm{AMH}$ is not detected from the small antral follicle stage onward (Hirobe et al., 1992; Baarends et al., 1995). Follicles showing signs of atresia also have decreased or no $\mathrm{AMH}$ expression, and expression is completely lost in corpora lutea (Fig. 1d). AMH is never found in primordial follicles, theca cells, oocytes or the interstitium (Fig. 1c,d; Ueno et al., 1989; Hirobe et al., 1992, 1994; Baarends et al., 1995; Durlinger et al., 2002). In rats, no differences occur during the oestrous cycle in the pattern of expression in follicles of the same class, although some heterogeneity has been observed in $\mathrm{AMH}$ mRNA expression in preantral and small antral follicles at oestrus and dioestrus (Hirobe et al., 1994; Baarends et al., 1995).

In contrast to $\mathrm{AMH}$, the $\mathrm{AMH}$ type II receptor does not show a sexually dimorphic pattern of expression. Expression is found in Müllerian duct mesenchymal cells and gonads of both sexes (Baarends et al., 1994; di Clemente et al., 1994b). In the postnatal ovary of mice and rats, AMHRII expression colocalizes with AMH in the granulosa cells, showing a similar expression window (Baarends et al., 1995; A. L. L. Durlinger and A. P. N. Themmen, unpublished). In addition, the theca cells of preantral and small antral follicles in rat ovaries express AMHRII (Ingraham et al., 2000).

The candidate AMH type I receptor ALK2 is also expressed in fetal and adult mouse ovaries (Visser et al., 2001), although its exact cellular and spatial pattern of expression remains to be determined; this is also true for expression of ALK3 mRNA in the ovaries of mouse fetuses (Dewulf et al., 1995). ALK6 is not expressed in the ovaries of mouse fetuses (Visser et al., 2001), but in the adult ovary, ALK6 is expressed in oocytes of small antral follicles, and in both the oocytes and granulosa cells of large antral follicles (Yi et al., 2001), and, therefore, it does not colocalize with ovarian AMHRII. More detailed expression studies are needed to establish the exact localization of all AMH type I receptors.

\section{AMH action in the ovary}

The specific patterns of expression of $A M H$ and $A M H R I I$ in the ovary indicate that $\mathrm{AMH}$ may play a role during follicle development and function. The first report on $\mathrm{AMH}$ action in the ovary showed that bovine $\mathrm{AMH}$ inhibited meiotic maturation of both denuded and cumulus-enclosed rat oocytes in vitro (Takahashi et al., 1986). However, Tsafriri et al. (1988) were not able to reproduce these results and no subsequent reports have been published on the effects of $\mathrm{AMH}$ on oocyte maturation. On the basis of the pattern of expression of the receptors described in this review, it is much more likely that $\mathrm{AMH}$ exerts its effect on ovarian follicles via the granulosa and theca cells, and not via the oocyte.

The generation of transgenic mice over-expressing $\mathrm{AMH}$ revealed that the presence of $\mathrm{AMH}$ during the fetal period is detrimental for ovarian development (Behringer et al., 1990). Female transgenic mice are infertile and most have a blind-ending vagina due to the absence of a uterus and oviducts. Although the ovaries are present at birth, in most animals the ovaries are devoid of germ cells and develop cord-like structures within 2 weeks after birth. In adult females, the ovaries have degenerated. Ovarian development appeared unaffected only in mice with the lowest serum AMH concentrations. Thus, in mice, the presence of $\mathrm{AMH}$ during the fetal period clearly has an impact on 

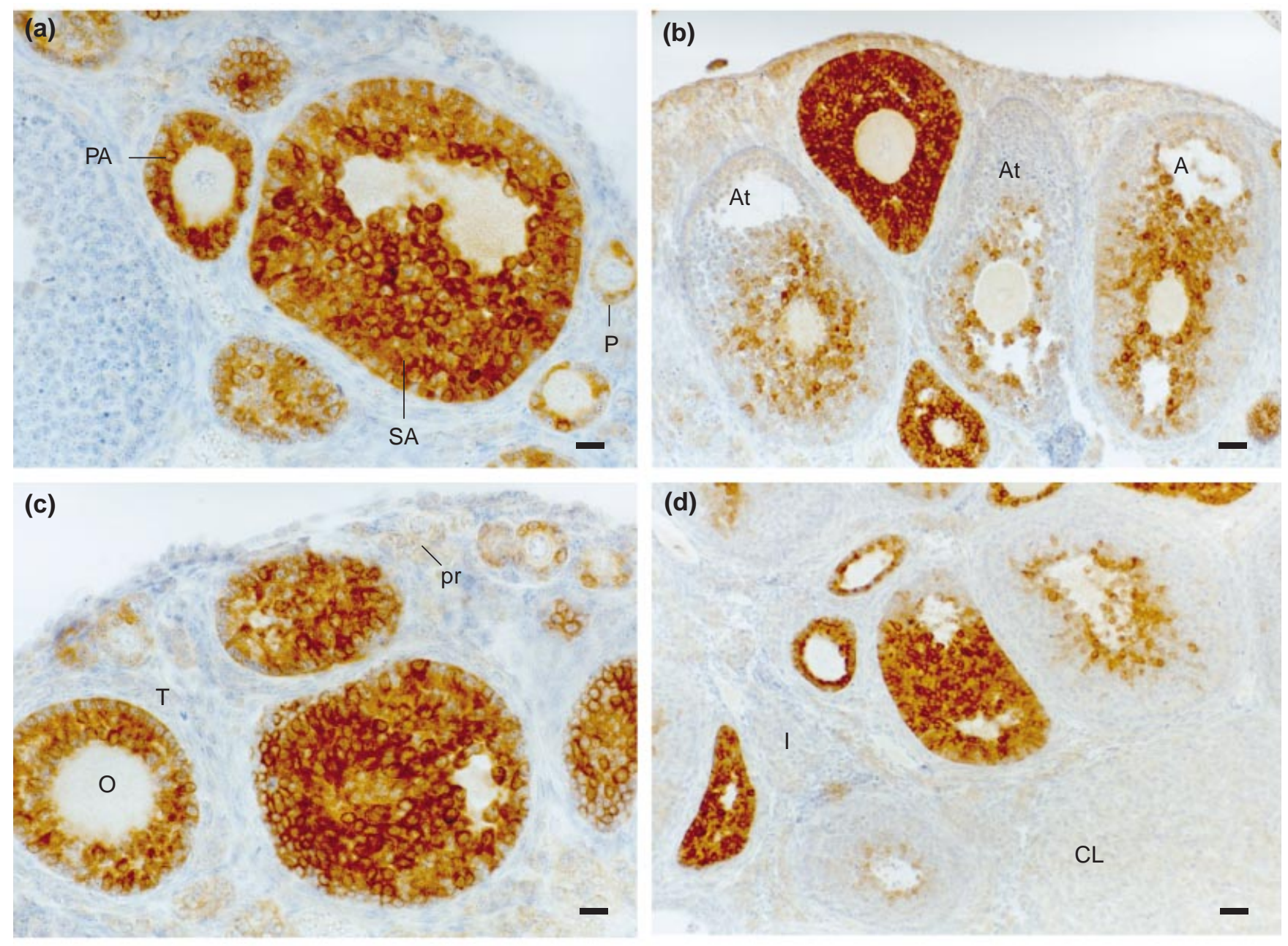

Fig. 1. Immunohistochemical localization of anti-Müllerian hormone (AMH) in a 30-day-old and a 4-month-old C57Bl/6J mouse ovary. (a) Section of an ovary of a 30-day-old mouse. AMH is found in granulosa cells from early primary follicles (P) and is highly expressed in granulosa cells of larger preantral (PA) and small antral (SA) follicles. (b) Section of an ovary of a 30-day-old mouse. AMH expression is decreased in antral (A) and atretic (At) follicles. The granulosa cells surrounding the antrum or the oocyte are the last cells to lose AMH expression. (c) Section of a 30-day-old mouse ovary. AMH expression is not present in primordial follicles (pr), oocytes (O) or theca cells (T). (d) Section of a 4-month-old mouse ovary. AMH expression is not found in the corpus luteum (CL) or the interstitium (I). Scale bars represent $(\mathrm{a}, \mathrm{c}) 20 \mu \mathrm{m}$ and $(\mathrm{b}, \mathrm{d}) 40 \mu \mathrm{m}$. (Adapted from Durlinger, 2000.)

ovarian and female germ cell development. However, inferences cannot be drawn from this mouse model with respect to a possible role of $\mathrm{AMH}$ in postnatal follicle development and function.

\section{AMH inhibits initiation of primordial follicle growth}

More insight into the role of $\mathrm{AMH}$ in the ovary was obtained from our studies of $\mathrm{AMH}$-deficient (AMHKO) mice. Male AMHKO mice retain their Müllerian duct derivatives and in some male mice Leydig cell hyperplasia is also observed. The AMHKO males are fertile, although their fertility is impaired for anatomical reasons. In female AMHKO mice, the lack of AMH does not affect fertility and initially no obvious ovarian abnormalities were observed (Behringer et al., 1994).
Despite this lack of an ovarian phenotype in AMHKO females, it is possible that $\mathrm{AMH}$ might be involved in subtle and long-term aspects of control of follicle development (Durlinger et al., 1999). This contention was based on the prominent and specific patterns of expression of $\mathrm{AMH}$ and AMHRII in the postnatal ovary and on the marked changes in expression of $\mathrm{AMH}$ and AMHRII mRNA during the oestrous cycle in rats (Baarends et al., 1995). A study of the entire follicle population in AMHKO females was performed to test this hypothesis (Durlinger et al., 1999) and revealed that, in the absence of $\mathrm{AMH}$, ovaries are depleted of their primordial follicles earlier than they are in control mice, as ovaries of adult and aged AMHKO females contain fewer primordial follicles than do ovaries of their wild-type littermates (Fig. 2). This decrease is caused by increased recruitment of primordial follicles in AMHKO females, as 


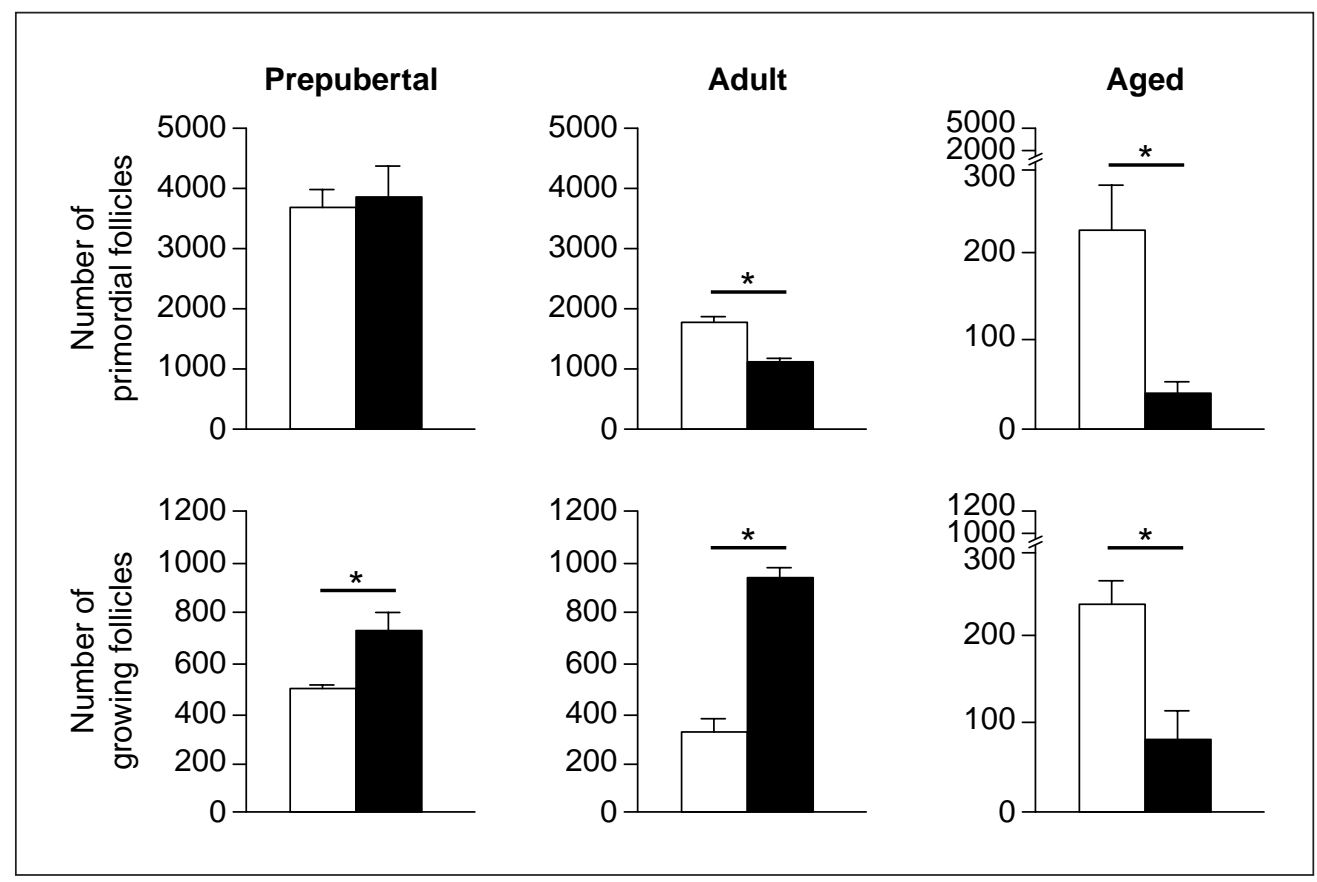

Fig. 2. Follicle population in prepubertal, adult and aged wild-type ( $\square$ ) and anti-Müllerian hormone knockout (AMHKO; $\mathbf{\square})$ female mice. Mice were killed at oestrus. Follicles were counted in both ovaries. Data represent the mean number of follicles per two ovaries \pm SEM (4-5 animals per genotype). The number of primordial follicles was significantly lower in adult (4 months of age) and aged (13 months of age) AMHKO female mice compared with the number in their wild-type littermates. Significantly more growing follicles were detected in prepubertal (25 days of age) and adult AMHKO female mice, whereas in aged AMHKO female mice the number of growing follicles was significantly lower. Asterisks indicate a significant difference $(P \leqslant 0.05)$. (Adapted from Durlinger et al., 1999.)

more preantral and small antral follicles (together referred to as small follicles) are found in prepubertal and adult AMHKO mice (Fig. 2). This increase in the number of small follicles is reflected by a twofold increase in total ovarian mass of adult AMHKO females relative to wild-type controls (Durlinger et al., 1999). Mice heterozygous for the amh mutation have an intermediate phenotype (not shown). This $\mathrm{AMH}$ gene dose-dependency indicates that ovarian $\mathrm{AMH}$ production or secretion may not be under stringent feedback control, but instead depends on the intrinsic activity of the gene itself.

The above-mentioned results indicate that $\mathrm{AMH}$ may be able to inhibit the initiation of follicle growth, a process also known as follicle activation or initial recruitment (McGee and Hsueh, 2000). Durlinger et al. (2002) confirmed this conclusion by a study in which neonatal mouse ovaries were cultured in vitro for 2 or 4 days in the absence or presence of $\mathrm{AMH}$. Ovaries of 2-day-old mice contain predominantly primordial follicles and some naked oocytes, but no growing follicles and, therefore, they provide an excellent model to investigate the influence of $\mathrm{AMH}$ on the recruitment of primordial follicles. $\mathrm{AMH}$ caused a $40-50 \%$ decrease in the number of growing follicles after 2 and 4 days of culture (Table 1). Consistent with these findings, a decreased expression of inhibin $\alpha$-subunit mRNA was found in $\mathrm{AMH}$-treated ovaries compared with control ovaries. In contrast, expression of AMHRII and the oocyte markers GDF9 and zona pellucida protein 3 (ZP3) were not influenced by $\mathrm{AMH}$. These results show that $\mathrm{AMH}$ is able to inhibit the initiation of primordial follicle growth and therefore functions as an inhibitory growth factor in the ovary during the early stages of folliculogenesis. This inhibitory effect is probably the result of a paracrine, (pre)granulosa cell-derived effect of $\mathrm{AMH}$ on the primordial follicle. An RNase protection assay showed that expression of AMHRII mRNA, which is essential for an effect of $\mathrm{AMH}$, is present in ovaries of 2-day-old mice (Durlinger et al., 2002). In addition, in situ hybridization studies demonstrated ovary-specific AMHRII expression in neonatal ovaries, although exact localization of the AMHRII expression to the pregranulosa cells was not possible because the radioactive AMHRII probe is best visualized using a microscope with dark field, making it difficult to discern specific structures or types of cell in neonatal ovaries (J. A. Visser, A. L. L. Durlinger and A. P. N. Themmen, unpublished).

The inhibitory effect of $\mathrm{AMH}$ on primordial follicle recruitment is consistent with our previous observation that the absence of, or reduced, AMH production in females results in an earlier depletion of the stock of primordial follicles. Therefore, the formation of preovulatory follicles would be expected to cease at a younger age in AMHKO 
Table 1. Inhibitory effect of anti-Müllerian hormone (AMH) on the number of growing follicles in an in vitro 2-day-old mouse ovarian culture

\begin{tabular}{lrl}
\hline Day of culture & Control & + AMH \\
\hline 2 & $81(100 \%)(n=9)$ & $50(59 \%) *(n=9)$ \\
4 & $153(100 \%)(n=11)$ & $97(66 \%)^{*}(n=11)$ \\
\hline
\end{tabular}

$n=$ number of ovaries examined.

$\%$ : the number of growing follicles of the control was set at $100 \%$.

*Indicates a significant difference from control (no AMH; $P \leqslant 0.05$ ).

females than in wild-type females, as the size of the primordial follicle pool is positively correlated with the duration of the reproductive lifespan of the female. This contention is clearly supported by, for example, the Baxdeficient female mouse model. Bax is involved in the execution of apoptosis, or programmed cell death, in many types of cell. In Bax-deficient females, the stock of primordial follicles shrinks much more slowly than it does in wild-type females, resulting in sustained ovarian function in aged Bax-deficient mice (20-22 months) (Perez et al., 1999).

A premature exhaustion of the follicle pool predicts an earlier cessation of ovulation in ageing animals. Indeed, when the presence of corpora lutea was used as an indication of ovulatory cycles, it was found that $56 \%$ of AMHKO females compared with only $18 \%$ of the aged wild-type females had stopped ovulating at 16-17 months of age (Durlinger, 2000).

Studies on the use of AMH as a marker for ovarian ageing in women have recently started. A study in young normoovulatory women showed that serum concentrations of AMH decrease over time and with advancing age before changes occur in other currently known ageing-related variables, such as serum concentrations of $\mathrm{FSH}$ and inhibin B, and the number of antral follicles (de Vet et al., 2002). Furthermore, a strong correlation was found between serum concentrations of $\mathrm{AMH}$ and the number of antral follicles, meaning that low serum $\mathrm{AMH}$ concentrations coincide with low numbers of antral follicles. A similar correlation was found on day 3 of the menstrual cycle in women undergoing in vitro fertilization (IVF) treatment (I. van Rooij, A. P. N. Themmen and E. R. te Velde, unpublished). As the age-related decrease in number of antral follicles corresponds to the age-related decrease in the number of primordial follicles (Scheffer et al., 1999), it can be postulated that serum AMH concentration is a good indication of the size of the ovarian follicle pool and, thus, of ovarian ageing. Support for the use of serum AMH concentration as a marker for ovarian response in women undergoing controlled ovarian stimulation for IVF is provided by the demonstration of an association between higher serum AMH concentration and a larger number of retrieved oocytes (I. van Rooij, A. P. N. Themmen and E. R. te Velde, unpublished). A similar observation has been made in another study in women undergoing IVF treatment (Seifer et al., 2002).

$\mathrm{AMH}$ is not the only regulator of initial recruitment. In addition to the inhibitory effect of $\mathrm{AMH}$, initiation of follicle growth can also be positively influenced by stem cell factor (SCF; Parrott and Skinner, 1999), GDF9 (Vitt et al., 2000), basic fibroblast growth factor (bFGF) (Nilsson et al., 2001) and nerve growth factor (NGF) (Dissen et al., 2001). It would be interesting to study the possible functional interactions of these different factors in initial recruitment. Indications for such an interaction have already been detected for SCF and GDF9. Expression of SCF mRNA is greatly increased in mice lacking GDF9 (GDF9KO), indicating that GDF9 may be one of the oocyte-secreted factors that negatively regulates SCF expression (Elvin et al., 1999b), although it seems more likely that this difference in expression of SCF mRNA in intact ovaries is caused by the radical change in composition of the follicle population in GDF9KO mice (Dong et al., 1996).

\section{AMH inhibits FSH-stimulated follicle growth}

Studies of female AMHKO mice have revealed that $\mathrm{AMH}$, in addition to its role in primordial follicle recruitment, plays a role in fine-tuning the sensitivity of growing follicles to FSH. Despite a lower serum FSH concentration, ovaries of 4-month-old AMHKO mice contain more growing follicles than do ovaries of their wild-type littermates (Durlinger et al., 1999), indicating that AMH may inhibit FSH-induced follicle growth. This hypothesis was confirmed by culture of mouse preantral follicles in vitro. Addition of $\mathrm{AMH}$ to the culture inhibited FSH-induced follicle growth in a time-dependent manner, as follicles cultured in the presence of $\mathrm{AMH}$ (at days 4 and 5 of culture) had a significantly smaller diameter. This AMH-induced inhibition in follicle growth was mainly the result of reduced granulosa cell proliferation, compared with FSH stimulation alone (Durlinger et al., 2001). In contrast, McGee et al. (2001) described a stimulatory effect of $\mathrm{AMH}$ on $\mathrm{FSH}$-induced growth of rat follicles. Although both the above studies used preantral follicles, species differences and absence or presence of serum (that is, other growth factors) in the culture medium may account for the opposing results (E. A. McGee, personal communication). The results of two in vitro studies in which exogenous AMH reduced expression of aromatase mRNA and decreased the number of $\mathrm{LH}$ receptors in cultured granulosa cells are in agreement with an inhibitory effect of $\mathrm{AMH}$ on follicle growth (di Clemente et al., 1994a). In addition, AMH opposes EGF-induced proliferation of cultured granulosa-luteal cells (Kim et al., 1992).

The inhibitory effect of $\mathrm{AMH}$ on FSH-stimulated follicle growth was also confirmed in an in vivo model in which follicle growth in the presence of high or low serum $\mathrm{FSH}$ concentrations was compared between AMHKO females and their wild-type littermates (Durlinger et al., 2001). This study showed that, in the presence of low serum FSH concentrations, more growing follicles were found in 


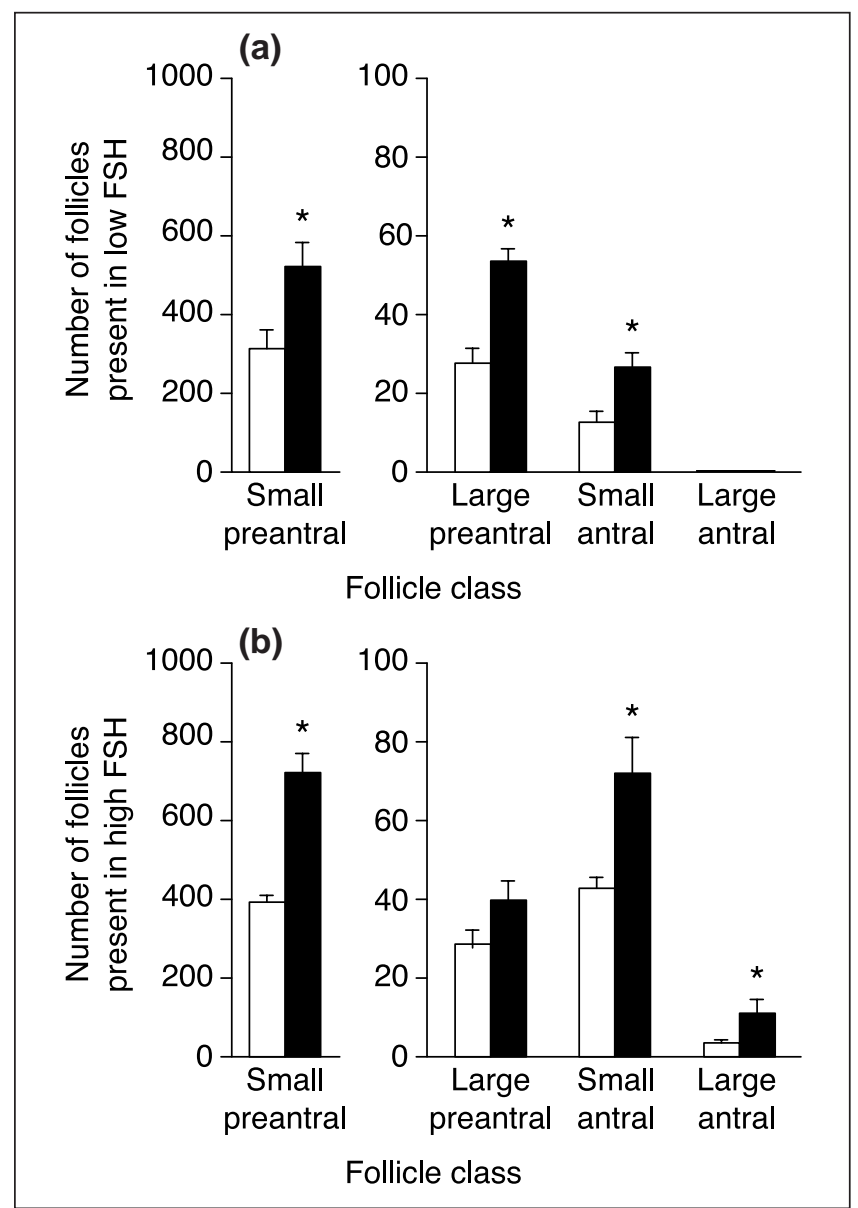

Fig. 3. Number of growing follicles in the presence of (a) low or (b) high serum FSH concentrations in prepubertal wild-type $(\square)$ and anti-Müllerian hormone knockout (AMHKO; $\mathbf{\square})$ female mice. Data represent the mean number of follicles per two ovaries \pm SEM ( $n=6$ animals per group). In the presence of both low and high serum $\mathrm{FSH}$ concentrations, more growing follicles are found in AMHKO females compared with wild-type females. Asterisks indicate a significant difference from wild-type females within the same treatment group $(P \leqslant 0.05)$. (Adapted from Durlinger et al., 2001.)

AMHKO females, whereas in the presence of high serum FSH concentrations, stimulation of follicle growth was more pronounced in AMHKO females than in wild-type females, both in terms of numbers and developmental stage (Fig. 3). These findings also indicate that, in the absence of $\mathrm{AMH}$, follicles are more responsive to $\mathrm{FSH}$.

This modulation of responsiveness to FSH by $\mathrm{AMH}$ could be very important during the process of cyclic recruitment. During cyclic recruitment in mice and rats, a group of follicles is recruited from the pool of large preantral and small antral follicles to continue growth to the preovulatory stage. Cyclic recruitment (McGee and Hsueh, 2000) takes place at oestrus, as a result of the secondary surge of FSH. This FSH peak is important for the number of follicles that are recruited (Hirshfield and De Paolo, 1981; van Cappellen et al., 1993). It is thought that, depending on the stage of development, each follicle requires a certain

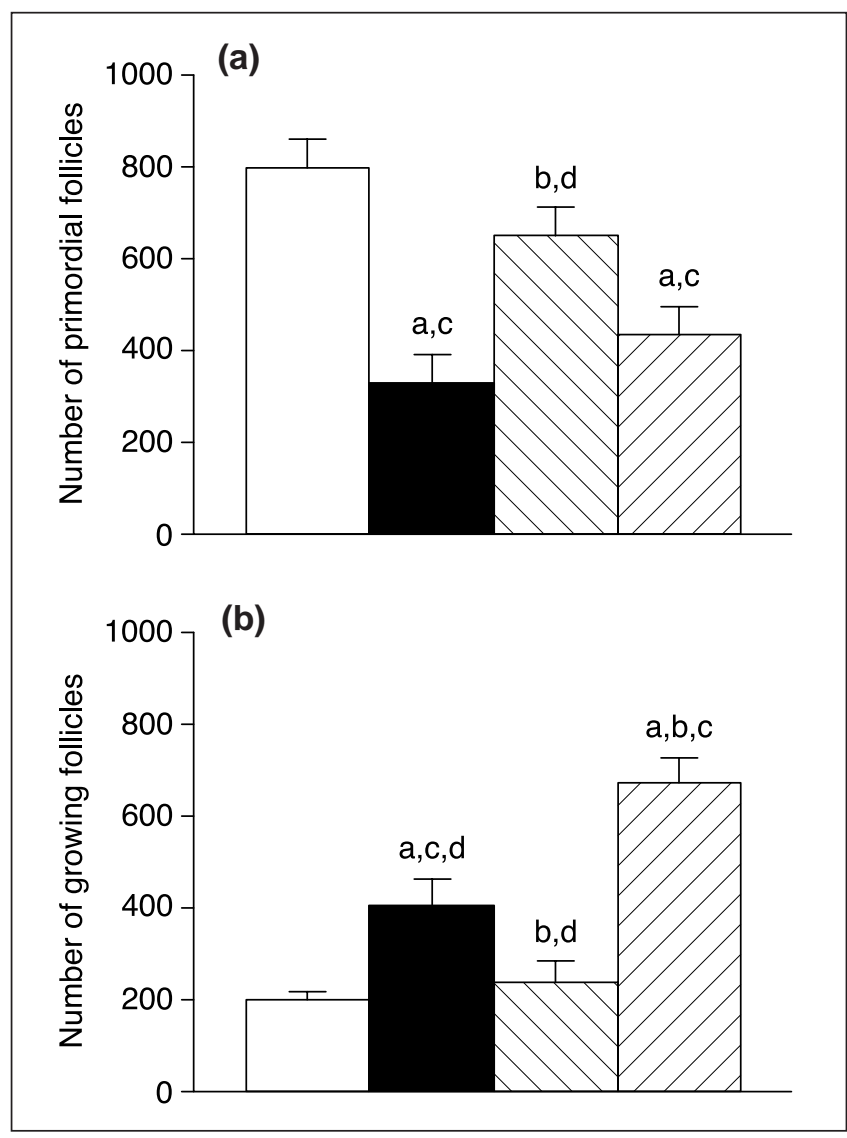

Fig. 4. Follicle population in adult wild-type $(\square)$, anti-Müllerian hormone knockout (AMHKO; $\mathbf{0}), \mathrm{FSH} \beta$ knockout (FSH $\beta K O ; \mathbb{\nabla})$, and $\mathrm{FSH} \beta$ and $\mathrm{AMH}$ knockout (FAKO; $\oslash$ ) female mice. Wild-type and AMHKO females were killed at oestrus. Follicles were counted in one ovary. Data represent the mean number of follicles per ovary $\pm \operatorname{SEM}$ ( $n=4$ animals per genotype). There is no significant difference for both the number of (a) primordial and (b) growing follicles between wild-type and FSH $\beta$ KO females. In both AMHKO and FAKO females, the number of primordial follicles is lower, whereas the number of growing follicles is higher compared with wild-type females. alndicates a significant difference compared with the wild type; bindicates a significant difference from AMHKO mice; cindicates a significant difference from FSHßKO mice; and dindicates a significant difference from FAKO females $(P \leqslant 0.05)$. (Adapted from Durlinger et al., 2001.)

concentration of $\mathrm{FSH}$ to continue growth; that is, each follicle displays its own FSH threshold concentration and this threshold concentration has to be exceeded to ensure growth to the preovulatory stage. This concept of an FSH threshold was developed after studies in humans (Brown, 1978). AMH may be one of the factors involved in determining the responsiveness of the follicle to FSH during cyclic recruitment. A role for $\mathrm{AMH}$ in cyclic recruitment is supported by the differential pattern of expression of $\mathrm{AMH}$ observed at oestrus in non-atretic large preantral and small antral follicles (Baarends et al., 1995). Although these follicles are morphologically indistinguishable, some follicles show high $\mathrm{AMH}$ expression whereas others have a much lower 


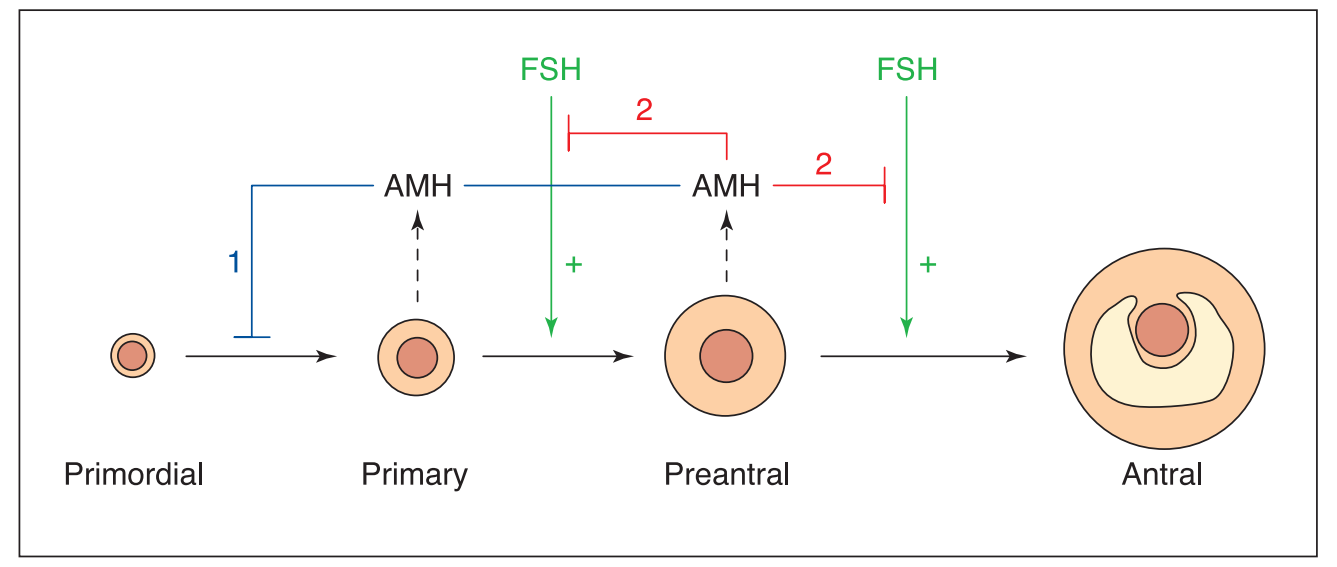

Fig. 5. Action of anti-Müllerian hormone $(A M H)$ in the postnatal ovary. AMH produced by preantral and small antral follicles in the postnatal ovary has two sites of action in the postnatal ovary. (1) It inhibits initial recruitment and (2) it inhibits the stimulatory effect of FSH on the growth of preantral and small antral follicles.

$\mathrm{AMH}$ expression. Low AMH expression would correlate with increased sensitivity to FSH, allowing these follicles to be selected for continued growth and ovulation in the next oestrous cycle. Indeed, in a preliminary study, using 5bromodeoxyuridine (BrDU) as a cell proliferation marker, in rats, more proliferating granulosa cells were found in follicles that expressed less $\mathrm{AMH}$, and vice versa (Durlinger, 2000).

The inhibitory action of $\mathrm{AMH}$ on growth stimulation by FSH can also be relevant for small preantral follicles. Although these follicles do not depend on FSH for their growth (Halpin and Charlton, 1988; Kumar et al., 1997), they are sensitive to FSH (van Cappellen et al., 1989; McGee et al., 1997). Therefore, complete loss of FSH production in mice would be expected to change preantral follicle growth. However, a study of the follicle population of 4-month-old FSH $\beta$-deficient (FSH $\beta K O$ ) and wild-type female mice revealed that the absence of FSH had no impact on the number of primordial and preantral-small antral follicles (Fig. 4) (Durlinger et al., 2001). The same study revealed that, in female mice lacking both $f s h \beta$ and amh expression (FAKO), the ovarian phenotype caused by AMH-deficiency is even more pronounced (Fig. 4), indicating that $\mathrm{AMH}$ may be a much more dominant regulator of early follicle growth than $\mathrm{FSH}$.

Thus, in addition to factors that stimulate preantral follicle growth, such as FSH (Halpin and Charlton, 1988; van Cappellen et al., 1989), stem cell factor (SCF; Parrott and Skinner, 1997) and GDF9 (Hayashi et al., 1999), inhibitory factors such as $\mathrm{AMH}$ are important in making preantral follicle growth a well-balanced process.

\section{AMH and cancer in women}

As $\mathrm{AMH}$ expression is restricted to ovarian granulosa cells in women, AMH may prove a useful serum marker of granulosa cell tumours (GTCs). Indeed, several studies showed an increased serum AMH concentration in women with both primary and recurrent GTCs (Gustafson et al., 1992; Rey et al., 1996; Silverman and Gitelman, 1996; Lane et al., 1999; Rey et al., 2000). An ultrasensitive enzymelinked immunosorbent assay (ELISA) has been developed using immunopurified monoclonal $\mathrm{AMH}$ antibodies to enhance the availability and sensitivity of serum $\mathrm{AMH}$ determination (Long et al., 2000), enabling researchers to detect the recurrences of GTCs at an early, preclinical stage.

AMH is not only a useful GCT marker but may also be applicable as a chemotherapeutic agent for ovarian epithelial tumours, as AMH causes regression of the Müllerian ducts, which arise from a common embryological precursor with the surface epithelium of the ovary, from which epithelial ovarian tumours originate (Scully, 1995). Several studies by P. Donahoe and co-workers have shown that AMH inhibits proliferation of cells derived from non-ovarian tumours (Fuller et al., 1985; Chin et al., 1991; Parry et al., 1992). More recent studies have demonstrated that growth of ovarian tumours of epithelial origin is also inhibited by $\mathrm{AMH}$ (Masiakos et al., 1999; Ha et al., 2000), causing the cells to accumulate in the G1 phase of the cell cycle and subsequently to undergo apoptosis (Ha et al., 2000). The inhibitory effect of AMH on the growth of epithelial ovarian tumour cells is probably mediated via AMHRII, as these tumour cells express AMHRII (Masiakos et al., 1999). AMH may also be able to act as a therapeutic agent for ovarian cancer in vivo, as was demonstrated in a study in which growth of human ovarian cancer cell line (IGROV-1) implanted under the renal capsule of the kidney of immunodeficient mice was inhibited in animals 'treated' with an AMH-expressing cell line (Stephen et al., 2001).

\section{Conclusion}

In conclusion, several studies on the function of $\mathrm{AMH}$ in the postnatal ovary indicate that $\mathrm{AMH}$ has at least two functions 
during follicular development (Fig. 5). First, AMH plays an inhibitory role during initial recruitment, when resting primordial follicles are initiated to grow, and second, it may modify preantral and small antral follicle growth by decreasing the $\mathrm{FSH}$-responsiveness of the follicle. The second effect may be important during cyclic recruitment, when certain large preantral and small antral follicles are recruited to grow on to the preovulatory follicle stage.

Furthermore, in women, there are indications that $\mathrm{AMH}$ can be used as a marker for ovarian ageing and as a marker for ovarian response in women undergoing IVF treatment. $\mathrm{AMH}$ has also proved to be a marker for granulosa cell tumours and has potential to be used as a therapeutic agent for ovarian epithelial tumours.

\section{References}

Key references are identified by asterisks.

Baarends WM, van Helmond MJ, Post $\mathbf{M}$ et al. (1994) A novel member of the transmembrane serine/threonine kinase receptor family is specifically expressed in the gonads and in mesenchymal cells adjacent to the Müllerian duct Development 120 189-197

Baarends WM, Uilenbroek JT, Kramer P, Hoogerbrugge JW, van Leeuwen EC, Themmen AP and Grootegoed JA (1995) Anti-Müllerian hormone and anti-Müllerian hormone type II receptor messenger ribonucleic acid expression in rat ovaries during postnatal development, the estrous cycle and gonadotropin-induced follicle growth Endocrinology 136 4951-4962

Behringer RR, Cate RL, Froelick GJ, Palmiter RD and Brinster RL (1990) Abnormal sexual development in transgenic mice chronically expressing Müllerian inhibiting substance Nature 345 167-170

Behringer RR, Finegold MJ and Cate RL (1994) Müllerian-inhibiting substance function during mammalian sexual development Cell $\mathbf{7 9}$ 415-425

Brown JB (1978) Pituitary control of ovarian function: concepts derived from gonadotrophin therapy Australian and New Zealand Journal of Obstetrics and Gynaecology 18 46-54

Cate RL, Mattaliano RJ, Hession C et al. (1986) Isolation of the bovine and human genes for Müllerian inhibiting substance and expression of the human gene in animal cells Cell 45 685-698

Chin TW, Parry RL and Donahoe PK (1991) Human Müllerian inhibiting substance inhibits tumor growth in vitro and in vivo. Cancer Research 51 2101-2106

Clarke TR, Hoshiya Y, Yi SE, Liu X, Lyons KM and Donahoe PK (2001) Müllerian inhibiting substance signaling uses a bone morphogenetic protein (BMP)-like pathway mediated by ALK2 and induces SMAD6 expression Molecular Endocrinology 15 946-959

de Vet A, Laven JS, de Jong FH, Themmen AP and Fauser BC (2002) AntiMüllerian hormone serum levels: a putative marker for ovarian aging Fertility and Sterility 77 357-362

Dewulf N, Verschueren K, Lonnoy O, Moren A, Grimsby S, Vande Spiegle K, Miyazono K, Huylebroeck D and Ten Dijke P (1995) Distinct spatial and temporal expression patterns of two type I receptors for bone morphogenetic proteins during mouse embryogenesis Endocrinology $1362652-2663$

di Clemente N, Goxe B, Rémy JJ, Cate RL, Josso N, Vigier B and Salesse R (1994a) Inhibitory effect of AMH upon the expression of aromatase activity and $\mathrm{LH}$ receptors by cultured granulosa cells of rat and porcine immature ovaries Endocrine 2 553-558

di Clemente N, Wilson C, Faure E et al. (1994b) Cloning, expression, and alternative splicing of the receptor for anti-Müllerian hormone Molecular Endocrinology 8 1006-1020

Dissen GA, Romero C, Hirshfield AN and Ojeda SR (2001) Nerve growth factor is required for early follicular development in the mammalian ovary Endocrinology 142 2078-2086
Dong J, Albertini DF, Nishimori K, Kumar TR, Lu N and Matzuk MM (1996) Growth differentiation factor-9 is required during early ovarian folliculogenesis Nature 383 531-535

Durlinger AL (2000) Ovarian Follicle Growth and Development: Role of Anti-Müllerian Hormone PhD Thesis, Erasmus University, Rotterdam

*Durlinger AL, Kramer P, Karels B, de Jong FH, Uilenbroek JT, Grootegoed JA and Themmen AP (1999) Control of primordial follicle recruitment by anti-Müllerian hormone in the mouse ovary Endocrinology 140 5789-5796

*Durlinger AL, Gruijters MJ, Kramer P et al. (2001) Anti-Müllerian hormone attenuates the effects of FSH on follicle development in the mouse ovary Endocrinology 142 4891-4899

*Durlinger AL, Gruijters MJ, Kramer P, Karels B, Ingraham HA, Nachtigal MW, Uilenbroek JT, Grootegoed JA and Themmen AP (2002) AntiMüllerian hormone inhibits initiation of primordial follicle growth in the mouse ovary Endocrinology 143 1076-1084

Elvin JA, Clark AT, Wang P, Wolfman NM and Matzuk MM (1999a) Paracrine actions of growth differentiation factor-9 in the mammalian ovary Molecular Endocrinology 13 1035-1048

Elvin JA, Yan C, Wang P, Nishimori K and Matzuk MM (1999b) Molecular characterization of the follicle defects in the growth differentiation factor 9-deficient ovary Molecular Endocrinology 13 1018-1034

Fuller AF, Jr, Krane IM, Budzik GP and Donahoe PK (1985) Müllerian inhibiting substance reduction of colony growth of human gynecologic cancers in a stem cell assay Gynecologic Oncology 22 135-148

Gouedard L, Chen YG, Thevenet L, Racine C, Borie S, Lamarre I, Josso N, Massagué J and di Clemente N (2000) Engagement of bone morphogenetic protein type IB receptor and Smad1 signaling by anti-Müllerian hormone and its type II receptor Journal of Biological Chemistry 27527 973-27978

Gustafson ML, Lee MM, Scully RE et al. (1992) Müllerian inhibiting substance as a marker for ovarian sex-cord tumor New England Journal of Medicine 326 466-471

Ha TU, Segev DL, Barbie D et al. (2000) Müllerian inhibiting substance inhibits ovarian cell growth through an Rb-independent mechanism Journal of Biological Chemistry 27537 101-37 109

Halpin DM and Charlton HM (1988) Effects of short-term injection of gonadotrophins on ovarian follicle development in hypogonadal (hpg) mice Journal of Reproduction and Fertility 82 393-400

Hayashi M, McGee EA, Min G, Klein C, Rose UM, van Duin M and Hsueh A) (1999) Recombinant growth differentiation factor-9 (GDF-9) enhances growth and differentiation of cultured early ovarian follicles Endocrinology 140 1236-1244

Hirobe S, He WW, Lee MM and Donahoe PK (1992) Müllerian inhibiting substance messenger ribonucleic acid expression in granulosa and Sertoli cells coincides with their mitotic activity Endocrinology 131 854-862

Hirobe S, He WW, Gustafson ML, MacLaughlin DT and Donahoe PK (1994) Müllerian inhibiting substance gene expression in the cycling rat ovary correlates with recruited or Graafian follicle selection Biology and Reproduction 50 1238-1243

Hirshfield AN and De Paolo LV (1981) Effect of suppression of the surge of follicle-stimulating hormone with porcine follicular fluid on follicular development in the rat Journal of Endocrinology 88 67-71

Imbeaud S, Belville C, Messika-Zeitoun L, Rey R, di Clemente N, Josso N and Picard JY (1996) A 27 base-pair deletion of the anti-Müllerian hormone type II receptor gene is the most common cause of the persistent Müllerian duct syndrome Human Molecular Genetics 5 1269-1277

Ingraham HA, Hirokawa Y, Roberts LM, Mellon SH, McGee E, Nachtigal MW and Visser JA (2000) Autocrine and paracrine Müllerian inhibiting substance hormone signaling in reproduction Recent Progress in Hormone Research 55 53-67; discussion 67-68

Josso N, Picard JY, Imbeaud S, di Clemente N and Rey R (1997) Clinical aspects and molecular genetics of the persistent Müllerian duct syndrome Clinical Endocrinology 47 137-144

Jost A (1947) Reserches sur la differenciation sexuelle de l'embryon de lapin Archives d'Anatomie Microscopique et de Morphologie Expérimentale $36271-315$ 
Kim JH, Seibel MM, MacLaughlin DT, Donahoe PK, Ransil BJ, Hametz PA and Richards CJ (1992) The inhibitory effects of Müllerian-inhibiting substance on epidermal growth factor induced proliferation and progesterone production of human granulosa-luteal cells Journal of Clinical Endocrinology and Metabolism 75 911-917

Kumar TR, Wang Y, Lu N and Matzuk MM (1997) Follicle stimulating hormone is required for ovarian follicle maturation but not male fertility Nature Genetics 15 201-204

Lane AH, Lee MM, Fuller AF, Jr, Kehas DJ, Donahoe PK and MacLaughlin DT (1999) Diagnostic utility of Müllerian inhibiting substance determination in patients with primary and recurrent granulosa cell tumors Gynecologic Oncology 73 51-55

Lee MM, Donahoe PK, Hasegawa T et al. (1996) Müllerian inhibiting substance in humans: normal levels from infancy to adulthood Journal of Clinical Endocrinology and Metabolism 81 571-576

Long WQ, Ranchin V, Pautier P et al. (2000) Detection of minimal levels of serum anti-Müllerian hormone during follow-up of patients with ovarian granulosa cell tumor by means of a highly sensitive enzyme-linked immunosorbent assay Journal of Clinical Endocrinology and Metabolism 85 540-544

*McGee EA and Hsueh AJ (2000) Initial and cyclic recruitment of ovarian follicles Endocrine Reviews 21 200-214

McGee EA, Perlas E, LaPolt PS, Tsafriri A and Hsueh AJ (1997) Folliclestimulating hormone enhances the development of preantral follicles in juvenile rats Biology of Reproduction 57 990-998

McGee EA, Smith R, Spears N, Nachtigal MW, Ingraham H and Hsueh AJ (2001) Müllerian inhibitory substance induces growth of rat preantral ovarian follicles Biology of Reproduction 64 293-298

Masiakos PT, MacLaughlin DT, Maheswaran S et al. (1999) Human ovarian cancer, cell lines, and primary ascites cells express the human Müllerian inhibiting substance (MIS) type II receptor, bind, and are responsive to MIS Clinical Cancer Research 5 3488-3499

Massagué J (1990) The transforming growth factor- $\beta$ family Annual Review of Cell Biology 6 597-641

Massagué J and Chen YG (2000) Controlling TGF- $\beta$ signaling Genes and Development 14 627-644

Mishina Y, Rey R, Finegold MJ, Matzuk MM, Josso N, Cate RL and Behringer RR (1996) Genetic analysis of the Müllerian-inhibiting substance signal transduction pathway in mammalian sexual differentiation Genes and Development $102577-2587$

Munsterberg A and Lovell-Badge R (1991) Expression of the mouse antiMüllerian hormone gene suggests a role in both male and female sexual differentiation Development 113 613-624

Nakao A, Imamura T, Souchelnytskyi S et al. (1997) TGF- $\beta$ receptormediated signalling through Smad2, Smad3 and Smad4 EMBO Journal 16 5353-5362

Nilsson E, Parrott JA and Skinner MK (2001) Basic fibroblast growth factor induces primordial follicle development and initiates folliculogenesis Molecular and Cellular Endocrinology 175 123-130

Parrott JA and Skinner MK (1997) Direct actions of kit-ligand on theca cell growth and differentiation during follicle development Endocrinology $1383819-3827$

Parrott JA and Skinner MK (1999) Kit-ligand/stem cell factor induces primordial follicle development and initiates folliculogenesis Endocrinology 140 4262-4271

Parry RL, Chin TW, Epstein J, Hudson PL, Powell DM and Donahoe PK (1992) Recombinant human Müllerian inhibiting substance inhibits human ocular melanoma cell lines in vitro and in vivo. Cancer Research 52 1182-1186

Perez GI, Robles R, Knudson CM, Flaws JA, Korsmeyer SJ and Tilly JL (1999) Prolongation of ovarian lifespan into advanced chronological age by Bax-deficiency Nature Genetics 21 200-203

Rajpert-De Meyts E, Jorgensen N, Graem N, Muller J, Cate RL and Skakkebaek NE (1999) Expression of anti-Müllerian hormone during normal and pathological gonadal development: association with differentiation of Sertoli and granulosa cells Journal of Clinical Endocrinology and Metabolism 84 3836-3844

Rey RA, Lhommé C, Marcillac I, Lahlou N, Duvillard P, Josso N and Bidart JM (1996) Anti-Müllerian hormone as a serum marker of granulosa cell tumors of the ovary: comparative study with serum alpha-inhibin and estradiol American Journal of Obstetrics and Gynecology 174 958-965

Rey R, Sabourin JC, Venara M, Long WQ, Jaubert F, Zeller WP, Duvillard P, Chemes H and Bidart JM (2000) Anti-Müllerian hormone is a specific marker of Sertoli- and granulosa-cell origin in gonadal tumors Human Pathology 31 1202-1208

Scheffer GJ, Broekmans FJ, Dorland M, Habbema JD, Looman CW and te Velde ER (1999) Antral follicle counts by transvaginal ultrasonography are related to age in women with proven natural fertility Fertility and Sterility 72 845-851

Scully RE (1995) Pathology of ovarian cancer precursors Journal of Cellular Biochemistry Supplement 23 208-218

Seifer DB, MacLaughlin DT, Christian BP, Feng B and Shelden RM (2002) Early follicular serum Müllerian-inhibiting substance levels are associated with ovarian response during assisted reproductive technology cycles Fertility and Sterility 77 468-471

Silverman LA and Gitelman SE (1996) Immunoreactive inhibin, Müllerian inhibitory substance, and activin as biochemical markers for juvenile granulosa cell tumors Journal of Pediatrics 129 918-921

Stephen AE, Masiakos PT, Segev DL, Vacanti JP, Donahoe PK and MacLaughlin DT (2001) Tissue-engineered cells producing complex recombinant proteins inhibit ovarian cancer in vivo. Proceedings National Academy of Sciences USA 98 3214-3219

Takahashi M, Koide SS and Donahoe PK (1986) Müllerian inhibiting substance as oocyte meiosis inhibitor Molecular and Cellular Endocrinology $\mathbf{4 7}$ 225-234

Taketo T, Saeed J, Manganaro T, Takahashi M and Donahoe PK (1993) Müllerian inhibiting substance production associated with loss of oocytes and testicular differentiation in the transplanted mouse XX gonadal primordium Biology of Reproduction 49 13-23

*Teixeira J, Saeed J, Manganaro T, Takahashi M and Donahoe PK (2001) Müllerian inhibiting substance: an instructive development hormone with diagnostic and possible therapeutic applications Endocrine Reviews 22 657-674

Tsafriri A, Picard JY and Josso N Immunopurified anti-Müllerian hormone does not inhibit spontaneous resumption of meiosis in vitro of rat oocytes Biology of Reproduction 38 481-485

Ueno S, Kuroda T, Maclaughlin DT, Ragin RC, Manganaro TF and Donahoe PK (1989) Müllerian inhibiting substance in the adult rat ovary during various stages of the estrous cycle Endocrinology 125 1060-1066

van Cappellen WA, Meijs-Roelofs HM, Kramer P and Van den Dungen HM (1989) Ovarian follicle dynamics in immature rats treated with a luteinizing hormone-releasing hormone antagonist (Org. 30276) Biology of Reproduction 40 1247-1256

van Cappellen WA, Osman P and Meijs-Roelofs HM (1993) Model of antral follicle dynamics during the 5-day cycle in rats based on measurement of antral follicle inflow Journal of Reproduction and Fertility 99 57-63

Visser JA, Olaso R, Verhoef-Post M, Kramer P, Themmen AP and Ingraham HA (2001) The serine/threonine transmembrane receptor ALK2 mediates Müllerian inhibiting substance signaling Molecular Endocrinology 15 936-945

Vitt UA, McGee EA, Hayashi M and Hsueh AJ (2000) In vivo treatment with GDF-9 stimulates primordial and primary follicle progression and theca cell marker CYP17 in ovaries of immature rats Endocrinology 141 3814-3820

Yi SE, LaPolt PS, Yoon BS, Chen JY, Lu JK and Lyons KM (2001) The type I BMP receptor BmprlB is essential for female reproductive function Proceedings National Academy of Sciences USA 98 7994-7999 